\title{
QUANTOS ANOS TEM PAULO FREIRE?
}

\author{
HOW OLD IS PAULO FREIRE?
}

\author{
¿QUÉ EDAD TIENE PAULO FREIRE?
}

A Madalena Freire

Walter Kohan ${ }^{1}$

https://orcid.org/0000-0002-2263-9732

${ }^{1}$ Universidade do Estado do Rio de Janeiro (UERJ); CNPq; FAPERJ, Rio de Janeiro, Rio de Janeiro Brasil. E-mail: wokohan@gmail.com

\section{Resumo}

O sentido principal deste texto é problematizar a relação entre o tempo da infância e o tempo adulto das instituições educativas. Para isso consideramos uma palestra de Paulo Freire na Faculdade de Direito da Universidade de São Paulo (USP), no dia 2 de junho de 1988, intitulada "Direitos Humanos e Educação Libertadora". O texto está composto de uma introdução, duas seções e as considerações finais. Na seção "Uma educação menina em direitos humanos", oferecemos as principais ideias apresentadas nessa intervenção pelo Patrono da Educação Brasileira e nos detemos numa referência que nos ajuda a pensar, numa segunda seção intitulada "A educação e o tempo da infância: quantas idades cabem numa idade?", a relação entre a educação e o tempo das idades ou os diferentes tempos que cabem numa idade. Finalmente, nas "Considerações finais", ocupamo-nos da pergunta que dá o título ao presente trabalho: "Quantos anos tem Paulo Freire?”, a partir de uma interlocução com ideias do poeta moçambicano Mia Couto.

Palavras-chave: Paulo Freire. Tempo. Idade. Infância. Mia Couto.

\begin{abstract}
The main purpose of this text is to problematize the relationship between childhood and adulthood in educational institutions. For this we considered a lecture by Paulo Freire at the Faculty of Law of the University of São Paulo (USP), on June 2, 1988, entitled "Direitos Humanos e Educação Libertadora". The text is composed of an introduction, two sections and final considerations. In the section "Uma educação menina em direitos humanos" we offer the main ideas presented in this intervention by the Patron of Brazilian Education and we focus on a reference that helps us think, in a second section entitled "A educação e o tempo da infância: quantas idades cabem numa idade?", the relationship between education and the time of ages or the different time periods that fit an age. Finally, in the "Considerações finais" we deal with the question that gives the title to the present work: "Quantos anos tem Paulo Freire?" inspired by ideas of the Mozambican poet Mia Couto.
\end{abstract}


KOHAN, W.

Keywords: Paulo Freire. Time. Age. Childhood. Mia Couto.

\section{Resumen}

El sentido principal de este texto es problematizar la relación entre el tiempo de la niñez y de la adultez en las instituciones educativas. Para ello consideramos una conferencia de Paulo Freire en la Facultad de Derecho de la Universidade de São Paulo (USP), el 2 de junio de 1988, titulada "Direitos Humanos e Educação Libertadora". El texto está compuesto por una introducción, dos apartados y consideraciones finales. En el apartado "Uma educação menina em direitos humanos", ofrecemos las principales ideas presentadas en esta intervención del Patrono de la Educación Brasileña y nos centramos en una referencia que nos ayuda a pensar, en un segundo apartado, titulado "A educação e o tempo da infância: quantas idades cabem numa idade?”, la relación entre la educación y el tiempo de edades o los diferentes tiempos que caben en una edad. Finalmente, en las "Considerações finais" abordamos la pregunta que da título al presente trabajo: “¿Cuántos años tiene Paulo Freire?”, a partir de un diálogo con las ideas del poeta mozambiqueño Mia Couto.

Palabras clave: Paulo Freire. Tiempo. Edad. Infancia. Mia Couto.

\section{Quantos anos tem Paulo Freire?}

Há perguntas de muito fácil resposta e outras de muito difícil resposta. Entre as perguntas que são de muito fácil resposta existem algumas que, uma vez respondidas, já não faz sentido continuar com elas, pois a curiosidade que as alimenta fica satisfeita, à procura de outros interrogantes. Ao contrário, há outras perguntas que, mesmo quando obtêm uma resposta rápida e contundente, seguem vivas, porque a resposta não esgota a curiosidade que está na sua base.

"Quantos anos tem Paulo Freire?" é a pergunta se que propõe para dar início à presente escrita. Não sei como os leitores e leitoras irão se relacionar com ela; espero que estejamos perante um exemplo desse último tipo de pergunta: aquela que, mesmo respondida, continua viva porque convida a pensar sobre algo que nenhuma resposta consegue responder. Serei ainda mais preciso. Num sentido, a pergunta que dá título a este texto é de muito fácil resposta. Paulo Freire nasceu em 19 de setembro de 1921, de modo que, hoje, 24 de julho de 2021, ele teria 99 anos e, em menos de dois meses, faria 100 anos. Muito provavelmente, quando este texto for lido, já se terá comemorado o centenário de Paulo Freire. Justamente por isso, neste ano, estão sendo organizadas tantas homenagens e tantos dossiês como o presente da revista Educação. Teoria e Prática. Aliás, a referida pergunta poderia ser formulada e respondida não apenas pela quantidade de anos que tem Paulo Freire, mas também por outras 
unidades de tempo: quantos meses, quantos dias, quantas horas, quantos minutos... e também quantas décadas, quantos séculos. O que mudaria seria apenas a unidade de medida e a consequente facilidade ou dificuldade em se estabelecer o número preciso dessas unidades transcorridas desde a sua data de nascimento. Segundo uma dessas medidas justamente, este ano Paulo Freire faria um século. Os símbolos fazem desse número algo significativo e, por isso, tantas (merecidas) homenagens, mas a pergunta poderia ter muitas outras unidades de medida e só mudaria o cálculo, visto que o procedimento para encontrar a respostas seria quase o mesmo.

A nossa pergunta, contudo, esperamos, embora possa ser respondida de modo mais ou menos simples, talvez não seja esquecida tão rapidamente, porque "quantos anos tem Paulo Freire?" parece estar sugerindo algumas outras coisas além de um número de anos. Qualquer leitor ou leitora minimamente atento já deve estar pensando que "algo mais" deve estar implícito na pergunta para que ela mereça ser apresentada num artigo para um dossiê acadêmico em homenagem a Paulo Freire. Com efeito, por que ou para que alguém tomaria essa pergunta como título de um artigo se ela tiver apenas uma resposta tão rápida e categórica? Estaria aparecendo algo assim como uma primeira suspeita de que Paulo Freire tinha uma relação especial com o tempo das idades que justificasse fazer dessa pergunta uma questão central para comemorar, num texto acadêmico, os 100 anos do Patrono da Educação Brasileira. Uma espécie de mistério, enigma, surpresa na forma de contar o tempo de uma vida.

Se essa suspeita se confirmar, estamos diante de uma pergunta especial, que teria uma espécie de sobrevida perante as pretensões de respondê-la. A questão pode parecer, mas nada tem de banal, especialmente se lembramos que Paulo Freire pensava que um dos problemas principais da educação brasileira é que ela vem sendo uma educação da resposta, e não uma educação da pergunta (FREIRE; FAUNDEZ, 2011), ou seja, no modo em que nos relacionarmos com a pergunta, haveria não apenas a questão do tema que a pergunta levanta (o tempo de uma vida), mas também a forma em que nos relacionamos com uma pergunta (qualquer que seja ela). Paulo Freire considerava, precisamente, que, nessa relação se joga uma questão fundamental de toda prática educativa. Em outras palavras, o problema de uma educação da resposta é que, justamente, ela pode, nas palavras do mestre pernambucano, "castrar a curiosidade necessária do educando que teria que se expressar na pergunta" (FREIRE, 1985, s/p). Chegamos às salas de aula, diz o mestre pernambucano, com respostas 
KOHAN, W.

"cujas perguntas se perderam no tempo" e damos respostas sem sequer escutar as perguntas dos nossos estudantes. Sendo assim, essa pedagogia da resposta tem várias implicações negativas: a) ela não mostra a conexão entre resposta e pergunta, ou seja, quais são as perguntas que as respostas que ofereceremos tentaram responder; b) ela não responde às perguntas que nossos estudantes podem ter porque sequer escuta as perguntas; c) ela pode castrar a curiosidade do educando que não encontra modos de expressão, pois suas perguntas não são escutadas.

As perguntas se perderam no tempo, afirma Paulo Freire, e essa afirmação nos lembra de nossa pergunta porque é por um tempo que nos estamos perguntando e também porque há muitas formas de se perder no tempo. Há uma forma mais habitual de se perder no tempo, que é quando não contamos bem o tempo ou não temos uma percepção clara dele e, portanto, não sabemos situar-nos claramente no tempo. Mas a expressão "perder-se no tempo" também pode estar sugerindo que estamos dando uma importância excessiva a um tipo de tempo ou a uma forma de experimentar o tempo e perdendo, ao mesmo tempo (!), outras formas de sentir ou experimentar o tempo. E isso também pode acontecer quando respondemos a uma pergunta pelo tempo de uma vida. Voltaremos a essa questão.

Numa pedagogia da pergunta, uma das questões centrais é não castrar a curiosidade que está na base das perguntas, de qualquer pergunta. Ao contrário, trata-se de, em primeiro lugar, escutar essas perguntas e cuidar, alimentar, manter viva a curiosidade que alimenta toda e qualquer pergunta. Paulo Freire não apenas pensava isso, quanto praticava essa relação com as perguntas em todas as ocasiões em que tinha oportunidade de se pronunciar ou responder a perguntas publicamente.

Nesse sentido, é bastante conhecido o exemplo que oferece, no livro que estamos comentando, de uma situação curiosa, significativa, a partir de uma intervenção sua na sua primeira visita a Argentina, numa periferia de Buenos Aires. Em ocasião de uma palestra fazendo parte de uma instância de formação, em vez de oferecer um discurso, Paulo convida os moradores de um bairro periférico a lhe fazerem perguntas para darem, assim, sentido comum ao tempo compartilhado. Rapidamente, um dos moradores afirma concordar com a ideia e faz o que Paulo Freire chama de "a pergunta fundamental": "o que significa mesmo perguntar?" (FREIRE; FAUNDEZ, 2011, p. 70). Paulo relata como ele tenta responder sem responder a essa e outras perguntas que lhe são feitas ("Em lugar de responder sozinho, tentei 
arrancar do grupo o que lhe parecia ser perguntar") e conclui que esse deveria ser um dos pontos principais de qualquer formação de educadores: o que significa perguntar evitando fazer dele um jogo intelectual e, ao contrário, uma oportunidade de viver o espanto, a curiosidade, o encantamento e a inquietação contidos no perguntar.

Pode haver um mundo, ou muitos mundos, por trás de uma pergunta e uma pedagogia da pergunta deve procurar manter o máximo de mundos abertos em cada pergunta; evitar as respostas aparentemente fáceis e manter vivos os sentimentos inquietos que cada pergunta pode esconder. Isso é o que faremos neste breve exercício de escrita. Ocupar-nos-emos de uma intervenção oral de Paulo Freire realizada numa Conferência na Universidade de São Paulo (USP), no Ciclo de Palestras de Direitos Humanos, a convite da Comissão de Justiça e Paz da Arquidiocese de São Paulo, na Faculdade de Direito da USP, no Largo de São Francisco, São Paulo, no dia 2 de junho de 1988. A palestra, intitulada "Direitos Humanos e Educação Libertadora", está reproduzida no livro Pedagogia dos sonhos possíveis, de Paulo Freire, com organização e apresentação de Ana Maria Araújo Freire, publicado pela editora da UNESP, a mesma que organiza o presente dossiê (FREIRE, 2001, p. 93-103). Apresentaremos inicialmente, na seção "Uma educação menina em direitos humanos", as principais ideias apresentadas nessa intervenção pelo Patrono da Educação Brasileira e nos deteremos numa referência que nos ajudará a pensar, numa segunda seção intitulada “A educação e o tempo da infância: quantas idades cabem numa idade?, a relação entre a educação e o tempo das idades ou os diferentes tempo que cabem numa idade. Finalmente, nas "Considerações finais" nos ocuparemos da pergunta principal desta escrita: "Quantos anos tem Paulo Freire?"

\section{Uma educação menina em direitos humanos}

A palestra de Paulo Freire na Universidade de São Paulo teve alguns elementos interessantes quanto à sua forma. Inicialmente, Paulo gastou algum tempo em apresentar uma situação inusitada: um certo medo que o acometeu quando chegou à universidade e viu o auditório repleto de gente; felizmente, pediram-lhe se dirigisse à sala dos professores e aguardasse mais uns dez ou quinze minutos, enquanto chegava ainda mais gente, o que lhe permitiu relaxar e pensar sobre as sensações que estava experimentando. Naquele momento, Paulo Freire já era um conferencista experiente, estava com 66 anos, já fizera inúmeras 
palestras em universidades do mundo inteiro e ainda sentia um certo medo e timidez diante de um auditório numeroso. O medo, afirmava, pode ser pedagógico porque mostra aos jovens que homens experientes, mais velhos, habituados a falar, mesmo assim não estão completamente seguros de si mesmos e ensina, também, uma forma de se relacionar com o medo: exteriorizá-lo, fazê-lo palavra, compartilhá-lo e, dessa forma, aliviá-lo.

Já entrando no assunto da palestra Paulo Freire partiu, como tantas outras vezes, da politicidade da educação. Com efeito, o primeiro direito humano é um direito humano negado para grande parte da população brasileira: o direito à educação. A educação encontra em si própria seu sentido político primeiro: o de dar-se a todas e todos aqueles a quem ela é negada. E o direito à educação dá lugar à enunciação de uma série de direitos fundamentais: o direito de comer, de vestir-se, de estar vivo, de decidir, de trabalhar, de ser respeitado, de dormir, de ter um travesseiro à noite para repousar e, finalmente, o direito de pensar, de preguntar, de caminhar, à solidão, à comunhão, de estar com, de estar contra, de brigar, falar, ler, escrever, sonhar e amar (FREIRE, 2001, p. 94-5). Desse modo, Paulo Freire apresenta a politicidade da educação como uma série de direitos que alguns adquirem apenas pelo fato de nascer na família em que nasceram, ao passo que muitos outros têm que lutar arduamente para poder disfrutar de alguns deles.

O que exige, então, a natureza política da educação, das educadoras e dos educadores? A princípio, uma opção é um tomar partido, a ausência de indiferença ou neutralidade. Devido a essa situação da sociedade em que habitamos e à falta mais absoluta de igualdade no fruir dos direitos humanos mais básicos, educar exige tomar partido a favor ou contra certos sonhos, mas nunca ser indiferente. Um educador ou educadora pode até se assumir como reacionário ou conservador, no sentido de alguém que faz de sua tarefa educacional um compromisso para manter o estado das coisas. O que um educador não pode é considerar que o que ele faz não tem nada a ver com a ordem política do mundo que em habita porque, de fato, fatalmente terá, seja para tentar mantê-lo ou transformá-lo.

Assim, é crucial perceber a natureza política da educação, porque é ela que vai determinar a perspectiva que um educador ou educadora adotará a respeito, por exemplo, dos direitos humanos. E também vai permitir estabelecer os limites que a educação tem em relação à transformação social. Efetivamente, neste texto, Paulo Freire é bastante prudente sobre as possibilidades transformadoras da educação: a educação, afirma, é limitada; mais 
ainda, ela não é a alavanca, o instrumento, a chave para a transformação social (FREIRE, 2001, p. 98). Claro que, o que aparenta ser uma limitação, torna-se, de fato, uma força, porque o poder transformador da educação surge quando ela percebe que não pode tudo e que é bastante limitada; porque, justamente, não podendo tudo, ela pode algo e é precisamente essa também a tarefa de educadoras e educadores: perceber o que, quando, como, onde e com quem é possível abrir espaços de transformação social, de modo que a educação não é a chave, mas também não é impotente e acaba sendo indispensável à transformação social. E parte da tarefa política de educadoras e educadores (que Paulo Freire, nessa conferência, menciona apenas com o feminino - "nós, educadoras" - para provocar o incômodo machista masculino dos que não se reconhecem na frase) é descobrir os espaços e organizar o que é possível fazer, mesmo que seja um mínimo de transformação em cada contexto.

Nesse aspecto, Paulo Freire oferece o que seria o sentido principal de uma educação em direitos humanos desde uma perspectiva progressistas ou libertadora: "aquela educação que desperta os dominados para a necessidade da briga, da organização, sem manipulações, com vistas à reinvenção do mundo, à reinvenção do poder" (FREIRE, 2001, p. 99). A questão da reinvenção do poder é por demais interessante e coloca Paulo Freire do lado dos grupos que entendem a transformação social não apenas a partir da tomada do poder, mas a partir de um novo jogo ou exercício de poder, com uma participação maior, mas também mais crítica e afetiva dos grupos populares tradicionalmente excluídos. E também resulta instigante porque Paulo Freire oferece uma distinção entre libertação e liberdade que é interessante para pensar a educação como ato político. O grande educador pernambucano afirma que a educação tem mais a ver com a libertação do que com a liberdade precisamente, porque não há liberdade e a libertação seria o combate para restaurar "a gostosura de ser livre que nunca finda, que nunca termina e sempre começa" (FREIRE, 2001, p. 100). É muito bonita essa referência à liberdade porque mostra também um certo caráter inacabado da luta política e da educação que a acompanha, uma certa tarefa de manter sempre viva e, no início, a luta política pelo gosto da liberdade, ou seja, manter a luta política como uma luta infantil, menina; uma luta que começa, mas nunca termina.

Seu gosto pelos começos é algo que Paulo Freire repete em muitas ocasiões. Por exemplo, na conversa com Myles Horton: "Eu gostaria de dizer alguma coisa sobre meu $N_{\sigma}$ começo - no qual ainda estou, porque estou sempre no começo, como você." (FREIRE; HORTON, 2018, p. 78). Coloquemos bastante atenção: Paulo Freire não apenas gosta, mas 
KOHAN, W.

está sempre no começo. Esse estar sempre na infância, ser um menino permanente foi bem percebido pelos cuidadores da Biblioteca Municipal de Ponsacco, na Toscana, Itália, que por isso o premiou, quando Paulo Freire tinha 68 anos, com o título honorário de "Bambino permanente" ("Menino permanente", A.M.A. FREIRE, 2010). Permanecer menino, não deixar a infância, seu tempo, sua forma de habitar o mundo: estar sempre no começo. Ou antes, como neste texto. O relato que se segue na conversa de Paulo Freire com Myles Horton é a sua lembrança de menino "conectivo", usando a expressão mágica da conjunção, diz Paulo, para fazer a ligação entre crianças de duas classes sociais diferentes: as que comiam pouco, mas comiam - e as que passavam fome. E a conexão estava no brincar, na felicidade que o jogar futebol na rua oferecia igualmente às crianças de todas as classes sociais.

Também não é a única vez em que a infância ou meninice aparece como um elogio para destacar um movimento político. Por exemplo, a própria Por uma pedagogia da pergunta termina com um elogio sonoro à revolução sandinista por ser uma "revolução menina”, e menina, ali, é um qualificativo que não tem o sentido etário, de uma curta idade; não é menina, Paulo Freire afirma explicitamente, por ser "recém-chegada", é menina "pela sua curiosidade, sua inquietação, seu gosto de perguntar, por não temer sonhar, por querer crescer, criar, transformar”. (FREIRE; FAUNDEZ, 2017, p. 231). O que faz viva uma revolução é o que faz viva uma educação em direitos humanos: manter-se menina no sentido de curiosa, inquieta, perguntadora, sonhadora, desejar sempre estar nos inícios de uma luta, na infância de um novo mundo. Por isso, a educação em direitos humanos sonha com uma outra sociedade:

\footnotetext{
Uma sociedade em que a gente tenha gosto de viver, de sonhar, de namorar, de amar, de querer bem. Esta tem que ser uma educação corajosa, curiosa, despertadora de curiosidade, mantenedora de curiosidade, por isso mesmo uma educação que, tanto quanto possível, vai preservando a menina que você foi, sem deixar que a sua maturidade a mate. (FREIRE, 2001, p. 101)
}

Assim, a sociedade sonhada é uma sociedade do sonhar, amar, gostar de viver e isso para todos os seus integrantes, e não apenas para alguns privilegiados. E a educação para tal sociedade é, sobretudo, uma educação curiosa e despertadora, mantedora e alimentadora de curiosidade; uma educação que preserva e mantém viva a nossa meninice, portanto uma educação menina da pergunta. 


\section{A educação e o tempo da infância: quantas idades cabem numa idade?}

Na sua palestra, Paulo Freire mostrou um certo cansaço, um fim de gripe que se manifestou na forma de uma forte tosse, e expressou uma certa necessidade de descansar, o que o fez, algo raríssimo nele, escusar-se de conversar depois de sua palestra. Talvez por isso, pelo seu estado gripal, na sua fala foi se aproximando cada vez mais da infância. Já no início, ele se mostrou menino, apresentando-se, no momento, "velho" de 66 anos, com o mesmo medo das almas penadas que o acometia, em cada noite, em sua meninice de poucos anos em Recife, presentes como elas estavam nas permanentes conversas dos mais velhos. Com o decorrer da sua palavra, contudo, a infância ou meninice se tornou cada vez mais presente até que, tendo já palestrado sobre a educação em direitos humanos, fez uma espécie de declaração de amor à infância:

Eu acho que uma das coisas melhores que eu tenho feito na minha vida, melhor do que os livros que eu escrevi, foi não deixar morrer o menino que eu não pude ser e o menino que eu fui, em mim. (FREIRE, 2001, p. 101)

Paulo Freire fez muitas coisas boas na vida e ele sabia muito bem disso. Dá, inclusive, testemunho da necessidade da falsa modéstia. Sabe do seu compromisso com a alfabetização das classes populares e das campanhas de alfabetização de que participou nos mais recônditos lugares do mundo. Escreveu uma vasta obra, com livros traduzidos para mais de vinte idiomas e, entre eles, a Pedagogia do Oprimido, o livro mais citado no mundo na área de Educação, de modo que não são poucas as coisas boas que Paulo Freire fez na sua vida. Ele considerava, porém, que havia algo melhor que fizera, que foi não deixar morrer, dentro dele, o menino que ele foi e o menino que ele não pôde ser, ou seja, a mais ampla meninice, tanto a vivida quanto a não vivida. E a seguir fez um depoimento sobre a sua relação com as idades que merece ser considerado sem muita presa:

Sexagenário, vejam como essa palavra já soa mal. Eu disse de propósito para ver como a história é isso. Na minha infância eu lia um jornal, Diário de Pernambuco ou Jornal do Comércio. E saía: faleceu, ontem, o sexagenário fulano de tal, féretro não sei quê... Hoje me dia, a geração jovem não conhece essa palavra. Tem que consultar o dicionário. Mas, sexagenário, tenho sete anos; sexagenário, eu tenho 
quinze anos; sexagenário, amo a onda do mar, adoro ver a neve caindo, parece até alienação. Algum companheiro meu de esquerda já estará dizendo: Paulo está irremediavelmente perdido. E eu diria a meu hipotético companheiro de esquerda: Eu estou achado: precisamente porque me perco olhando a neve cair. Sexagenário, eu tenho 25 anos. Sexagenário, eu amo novamente e começo a criar uma vida de novo. (FREIRE, 2001, p. 101)

Há uma primeira reflexão sobre a palavra "sexagenário", uma dessas palavras que era bastante habitual na juventude de Paulo Freire e que depois caiu um pouco em desuso. É quase que um protesto habitual, nostálgico, de um sexagenário que sente o passar do tempo no desuso de algumas palavras que lhe são caras. É uma espécie de lamento inicial. A seguir, contudo, lança uma profunda provocação sobre sua relação intensa, sendo ele sexagenário, com todas as idades.

Talvez seja oportuno relembrarmo-nos o título do presente texto: “Quantos anos tem Paulo Freire?". A pergunta se mostra oportuna porque parece que Paulo Freire não se percebe apenas com o número de anos ditado pela sua idade. Ou seja, ele tem, no momento da conferência, 66 anos, é um sexagenário, mas parece que não é apenas um sexagenário. Ele tem também muitas outras idades, de modo que a nossa pergunta seria respondida pelo próprio Paulo Freire de muitas formas: ele tem 66 anos, mas também tem 7 anos, 15 anos, 25 anos. Acaso enlouqueceu ou estava muito afetado pela gripe para dizer que tinha todas essas idades ao mesmo tempo?

Certamente, não. Paulo Freire quis dizer que, numa mesma idade cronológica, podem conviver muitas possibilidades de existência humana. A infância mais uma vez ganha destaque. Como um menino, sentindo-se no tempo de menino, ele adorava se perder no tempo, a onda do mar e ver a neve cair, brincar de boneco de neve; a sua experiência de tempo extrapolava a idade que tinha. Ele viveu muitos tempos numa idade só. Assim, conseguiu ter algumas experiências de um tempo infantil em que nos perdemos no tempo de brincar, de se perder no tempo, esquecer o tempo do relógio, durante uma experiência lúdica ou estética. No campo da militância política, alguns veem isso como um perigo, uma perda, um sem sentido. Para outros, como Paulo Freire, são sinônimo de uma política meninamente revolucionária, portanto curiosa, inquieta, perguntadora. 


\section{Considerações finais: quantos anos tem Paulo Freire?}

É tempo (momento ou idade?) de retomar nossa pergunta inicial: quantos anos tem Paulo Freire? O que parecia uma pergunta de resposta simples e única tornou-se uma pergunta de muitas respostas. Paulo Freire, com 66 anos, afirmou que não só tinha 66 anos, mas também muitas outras idades simultaneamente. Ofereceu o que pareciam ser apenas exemplos para problematizar as respostas únicas e aparentemente indubitáveis. Como se ele tivesse infinitas idades numa mesma idade, num tempo só. Ou como se ele se sentisse habitando muitos tempos numa idade só.

A poesia é uma forma de revelação de mistérios que pode nos ajudar a pensar a pergunta que nos ocupa e a confusão de idades e tempos em que parecemos estar envolvidos. Mia Couto, poeta moçambicano, fez uma bela intervenção no Congresso de Leitura (COLE) em Campinas, em 2007, intitulada "Quebrar armadilhas", num evento de que também sobe participou Paulo Freire em 1981. A forma como Mia Couto pensa a tarefa da poesia não é completamente afastada de como Paulo Freire pensa a educação: "Compete-nos desarmadilhar o mundo para que ele seja mais nosso e mais solidário." (COUTO, 2009, p. 95). Desarmadilhar: verbo que surge de uma curiosidade, uma inquietação, uma infância. Na palestra, o poeta propõe uma série de armadilhas a serem quebradas ou desarmadas: a armadilha da língua, a armadilha de nosso próprio olhar, a armadilha da realidade, a armadilha da identidade e a da hegemonia da escrita. Assim, ensinar a ler é ensinar a traspor o imediato, a escolher entre sentidos visíveis e invisíveis, a pensar, no sentido de cuidar e curar, de uma terapia que nos ajuda a sair de nós mesmos, da identidade que temos construído e que nos ata a uma imagem única de nós próprios. O poeta não a menciona explicitamente, mas poderíamos incluir o desejo de livrarmo-nos da armadilha do tempo das idades.

Precisamente, uma das armadilhas que precisamos quebrar diz respeito ao tempo lineal, quantitativo, produtivo, que opera como uma emboscada nas instituições educacionais; com efeito, elas estão governadas pelos programas, diretrizes curriculares e planificações, que se desdobram em semestres, anos, períodos, como bem marcam os fluxogramas e cronogramas; elas contam um tempo sem presente, pois é a numeração do movimento e sua ordenação em passado e futuro, resultando no tempo das idades, aquele com que medimos também a temporalidade de uma vida e a organizamos em etapas ou fases: o que são 66 anos afinal? Sessenta e seis movimentos de um ano... O que é um ano? Trezentos e sessenta e cinco 
KOHAN, W.

movimentos de um dia... O que é um dia? Vinte e quatro movimentos de uma hora... O que é uma hora? Sessenta movimentos de um minuto... O que é um minuto? Etc., etc., etc. Sob essa lógica, nossa experiência vital está limitada a contar movimentos qualitativamente indiferenciados e sem graça. Tempo numerado, quantificado, desqualificado. Com efeito, esse tempo, que os gregos chamavam de khrónos (KOHAN, 2004), é apenas movimento numerado... e nada mais. É um tempo sem qualidade porque justamente cada movimento precisa ser qualitativamente indiferenciado para poder medir a quantidade dos movimentos, e não sua qualidade. É um tempo muito útil, que organiza a vida e as instituições, que permite planejar e dosificar, mas que reduz a vida a uma sequência sucessiva, consecutiva e irreversível.

Mia Couto fala em "quebrar armadilhas", de um outro tempo, circular, próprio da rica cosmogonia rural africana. E conta um episódio de um menino de rua que atravessou a cidade para entregar-lhe um livro que tinha a sua foto na capa; o menino tinha visto o livro nas mãos de uma estudante à saída da escola e, como tinha a fotografia de Mia Couto, pensou que lhe pertencia e que tinha sido roubado dele. E acrescenta:

\footnotetext{
Lembrei aqui o episódio do menino de rua porque tudo começa aí, na infância. A infância não é um tempo, não é uma idade, uma coleção de memórias. A infância é quando ainda não é demasiado tarde. É quando estamos disponíveis para nos surpreendermos, para nos deixarmos encantar. Quase tudo se adquire nesse tempo em que aprendemos o próprio sentimento do Tempo. A verdade é que mantemos uma relação com a criança como se ela fosse uma menoridade, uma falta um estado precário. Mas a infância não é apenas um estágio para a maturidade. É uma janela que, fechada ou aberta, permanece viva dentro de nós. (COUTO, 2009, p. 103-4.)
}

Tudo começa na infância, diz o poeta. A infância não é uma idade, mas um tempo ou, em todo caso, a idade em que aprendemos o sentimento do tempo. Um tempo circular, não linear como o que governa, e somos ensinados a medir nossas vidas nas instituições educativas. $\mathrm{Na}$ infância, não aprendemos o tempo do relógio, mas a sentir propriamente o tempo: por isso na infância nunca é demasiado tarde, porque não existe "tarde" no tempo de infância. Na infância aprendemos a importância de esperar, de chegar junto, de brincar inteiramente, sem pensar em outra coisa e sem olhar muito para o relógio porque, se o fizermos, seremos presos pela angústia de sentir o tempo passar demasiadamente rápido, o 
que nos impediria de brincar no tempo presente da infância. Aprendemos a nos inquietar com o mundo, a nos surpreender, a nos deixar encantar.

Esse sentimento de tempo que aprendemos na infância é absolutamente essencial para educar, a qualquer idade, pessoas de qualquer idade. Talvez por isso Paulo Freire considerava que uma das melhores coisas que havia feito em sua vida era manter vivo esse sentimento de tempo menino dentro de si. Manter vivo o menino que foi e que não pôde ser era manter viva uma curiosidade, um encantamento, um sentimento de que nunca é demasiado tarde, sentimento que ele próprio, na sua idade menina, nem sempre pôde experimentar. Talvez por isso sentia que habitava simultaneamente muitas idades.

Quantos anos tem Paulo Freire? Qual é a sua idade? Qual o seu tempo? Se, em 1988, a pergunta pelos anos de Paulo Freire tem mais de uma resposta, quantas respostas terá essa mesma pergunta em 2021, já passados mais de 24 anos de sua morte, e prestes a se cumprirem 100 anos do seu nascimento? Quantas idades e quantos tempos cabem em 100 anos de uma vida meninamente educadora? Quantas perguntas cabem numa pergunta? Como Paulo Freire, adoro estar nos começos e por isso sinto uma alegria intensamente menina de poder terminar este texto com muitas perguntas, ou seja, com muitos começos para poder seguir pensando.

\section{Referências}

COUTO, Mia. E se Obama fosse africano? E outras intervenções. Ensaios. São Paulo: Companhia das Letras, 2009.

FREIRE, Ana Maria Araújo. "Foreword". In: WILSON, Tom; PARK, Peter; COLÓNMUÑIZ, Anaida (eds.). Memories of Paulo. Rotterdam: Sense, 2010, p. xix-xxix

FREIRE, Paulo. Resgate. Encontro com Paulo Freire. Campinas: TV UNICAMP, 1985. Disponível em:

https://www.youtube.com/watch?v=5yRyAXPXHmA\&ab_channel=TVUnicamp. Acesso em: 24 jul. 2021).

FREIRE, Paulo. Pedagogia dos sonhos possíveis. Organização e apresentação de Ana Maria Araújo Freire São Paulo: UNESP, 2001.

FREIRE, Paulo. A importância do ato de ler. Em três artigos que se complementam. São Paulo: Cortez, 2011. 
KOHAN, W.

FREIRE; Paulo; FAUNDEZ, Antonio. Por uma pedagogia da pergunta. São Paulo: Paz e Terra, 2011.

FREIRE, Paulo; GUIMARÃES, Sérgio. (1982). Sobre educação: diálogos. Rio de Janeiro: Paz e Terra, 1982.

FREIRE, Paulo; HORTON, Myles. We made the road by walking. Philadelphia: Temple University Press, 1990 [O caminho se faz caminhando: conversas sobre educação e mudança social. Organizado por Brenda Bell, John Gaventa e John Peters. Tradução de Vera Josceline. Notas de Ana Maria Araújo Freire. 1. reimp. Petrópolis: Vozes, 2018].

KOHAN, Walter Omar. A infância da educação: o conceito devir-criança. In: Lugares da infância: filosofia. Rio de Janeiro: DP\&A, 2004, p. 51-68.

Recebido em 28/07/2021

Aprovado em 13/09/2021

Publicado em 29/10/2021 